\title{
Risky Decision Making in Substance Dependent Adolescents with a Disruptive Behavior Disorder
}

\author{
Dennis J. L. G. Schutter • Irene van Bokhoven • \\ Louk J. M. J. Vanderschuren • John E. Lochman • \\ Walter Matthys
}

Published online: 14 December 2010

(C) The Author(s) 2010. This article is published with open access at Springerlink.com

\begin{abstract}
Of all psychiatric disorders, the disruptive behavior disorders (DBDs) are the most likely to predispose to substance dependence (SD). One possible underlying mechanism for this increased vulnerability is risky decision making. The aim of this study was to examine decision making in DBD adolescents with and without SD. Twenty-five DBD adolescents (19 males) with SD (DBD+SD), 28 DBD adolescents (23 males) without SD (DBD-SD) and 99 healthy controls (72 males) were included in the study. DBD adolescents with co-morbid attention deficit/ hyperactivity disorder
\end{abstract}

D. J. L. G. Schutter

Department of Experimental Psychology, Utrecht University,

Heidelberglaan 2,

3584 CS Utrecht, the Netherlands

I. van Bokhoven $\cdot$ W. Matthys $(\square)$

Department of Child and Adolescent Psychiatry,

Rudolf Magnus Institute of Neuroscience,

University Medical Center Utrecht,

3584 CX Utrecht, the Netherlands

e-mail: w.matthys@umcutrecht.nl

L. J. M. J. Vanderschuren

Department of Neuroscience and Pharmacology,

Rudolf Magnus Institute of Neuroscience,

University Medical Center Utrecht,

3548 CG Utrecht, the Netherlands

L. J. M. J. Vanderschuren

Department of Animals in Science and Society,

Division of Behavioural Neuroscience,

Faculty of Veterinary Medicine, Utrecht University,

3584 CM Utrecht, The Netherlands

J. E. Lochman

Department of Psychology, The University of Alabama,

Tuscaloosa, AL 35487-0348, USA
(ADHD) were excluded. Risky decision making was investigated by assessing the number of disadvantageous choices in the Iowa gambling task. DBD+SD made significantly more risky choices than healthy controls and DBD-SD. Healthy controls and DBD-SD did not differ on risky decision making. These results suggest that risky decision making is a vulnerability factor for the development of SD in a subgroup of adolescents with DBD without ADHD.

Keywords Decision making · Disruptive behavior disorder $\cdot$ Iowa gambling task $\cdot$ Substance dependence

Of all psychiatric disorders, the Disruptive Behavior Disorders (DBDs), i.e., Conduct Disorder (CD) and Oppositional Defiant Disorder (ODD), are the most likely to predispose to substance dependence (SD) (Costello et al. 2003; Disney et al. 1999; Fergusson et al. 2007; KimCohen et al. 2003; Merikangas and Avenevoli 2000; Rutter et al. 2006; Young et al. 1995). The mechanisms underlying this increased vulnerability in the DBDs, however, remain poorly understood. Behavioral genetic research has shown that adolescent $\mathrm{CD}$, adult antisocial behavior and SD share a highly heritable general vulnerability (Hicks et al. 2004). This shared genetic vulnerability may be manifested already at an early age in the form of abnormalities in the sensitivity for reward and punishment as well as deficiencies in the ability to balance immediate rewards against long-term negative consequences.

In support of this notion, response perseveration, i.e., the tendency to continue a previously rewarded response that is now punished, has been repeatedly demonstrated in children and adolescents with DBDs (Daugherty and Quay 1991; 
Matthys et al. 1998; Shapiro et al. 1988; Van Goozen et al. 2004), in children with psychopathic tendencies (O'Brien and Frick 1996), and in young non-alcoholic men with a multigenerational family history of alcoholism (Giancola et al. 1993). Perseverative behavior may contribute to impairments in decision making by rendering individuals unable to shift their behavior away from immediate rewards that are associated with even larger future punishments. This may be of relevance for SD, since continued drug use despite explicit knowledge of its negative consequences is a defining characteristic of SD (American Psychiatric Association 2000). Indeed, disturbances in the balance between shortterm gains and long-term losses have been observed both in adults with SD and adults with antisocial disorders (Bartzokis et al. 2000; Bechara et al. 2001; Grant et al. 2000; Mazas et al. 2000).

Although a variety of studies have investigated decision making in children and adolescents with DBD, comorbidity with attention deficit/hyperactivity disorder (ADHD) has not been taken into account. Impaired decision making has been found in DBD adolescents (Fairchild et al. 2009). However, in the Fairchild et al. (2009) study the sample consisted of adolescents with DBD with or without ADHD. It is important to take the comorbidity of DBDs with ADHD into account, not only because impaired decision making has been found in adolescents with ADHD (Toplak et al. 2005), but also because children with ADHD are at risk for SD (Biederman et al. 2006). Likewise, in a recent study by Luman et al. (2010) deficits in decision making in children with ODD may have been caused by ADHD, as 16 of the 18 children with ODD included in this study also met criteria of ADHD. Finally, in the study on decision making by Ernst et al. (2003) the sample was heterogeneous, consisting of adolescents with ADHD without co-morbidity, adolescents with DBD without co-morbidity, and ADHD adolescents with a history of mood disorders but without acute symptoms. In sum, it remains unclear whether decision making deficits are associated with DBD, ADHD, or both.

To assess decision making in children and adolescents with DBD (Ernst et al. 2003; Fairchild et al. 2009; Luman et al. 2010) and in adults with SD (Bechara et al. 2001; Bechara et al. 2002) gambling tasks such as the Iowa gambling task (IGT) are often used. The IGT measures decision-making processes by simulating real-life decisions involving reward, punishment, and uncertainty of outcomes. During the IGT, healthy participants learn to favor immediate small over large rewards to avoid large future punishments. Interestingly, low punishment sensitivity has been associated with response perseveration in boys with DBD (Matthys et al. 2004). In addition, high reward sensitivity correlates with overall risky decision making, impulsivity and substance use (Blum et al. 2000; Giancola et al. 1993). Thus, differences in the balance between reward and punishment sensitivity, as well as perseverative behavior associated with DBD and SD may contribute to impaired decision making in these disorders.

Alternatively, animal studies have shown that exposure to drugs of abuse may cause impairments such as hypersensitivity to reward, hyposensitivity to punishment and perseverative behavior, that may contribute to disturbances in decision making (Deroche-Gamonet et al. 2004; Fletcher et al. 2005; Jentsch et al. 2002; Roesch et al. 2007; Schoenbaum et al. 2004; Schoenbaum and Setlow 2005; Vanderschuren and Everitt 2004). This suggests that risky decision making may not only be a cause, but could also be a consequence of SD.

The aim of the present study was to examine the relationship between decision making and SD in DBD adolescents. To that end, we compared risky decision making in DBD adolescents with (DBD+SD) and without SD (DBD$\mathrm{SD}$ ), and healthy controls. In order to exclude possible contributions of ADHD to decision making deficits in DBD, DBD adolescents with co-morbid ADHD were excluded from the study. We anticipated that if impaired decision making is associated with DBD, then DBD+SD and DBD-SD will demonstrate decision making deficits when compared with healthy controls. Alternatively, if impaired decision making is a vulnerability factor for SD in DBD then among adolescents with DBD only those with SD (DBD+SD) will demonstrate deficits in decision making.

\section{Methods}

\section{Participants}

Fifty-three adolescents (mean \pm SD age, $17.2 \pm 1.7$ years) meeting the criteria for DBD, that is either CD or ODD in accordance with the DSM-IV-TR (American Psychiatric Association 2000) were recruited from judicial and forensic/orthopsychiatric institutions for youth in the Netherlands, and compared to 99 adolescents in a healthy control group (HC). ODD was included because institutionalization precludes the occurrence of some behaviors or symptoms that would normally result in a $\mathrm{CD}$ diagnosis. The $\mathrm{HC}$ group (mean \pm SD age, $17.5 \pm 1.9$ years) consisted of a selected sample from an existing database of participants (ZonnevylleBender et al. 2007) and newly recruited volunteers from vocational training schools in the Netherlands. None of the DBD or HC adolescents had a DSM-IV-TR diagnosis of ADHD or schizophrenia. SD was diagnosed according to DSM-IV-TR (American Psychiatric Association 2000). Psychiatric diagnoses of $\mathrm{CD}$, ODD, ADHD and SD were obtained using the NIMH Diagnostic Interview Schedule for Children-Child Version (DISC-IV-C) (Shaffer et al. 2000). 
The NIMH DISC-IV-C interview was performed by a trained psychologist. The proportion of CD/ODD diagnoses in the DBD-SD (24/4) and the DBD+SD (21/5) was equal, $\chi^{2}=$ 0.03: $p=0.86$. None of the HC included in the present sample had a diagnosis of SD. General intellectual functioning was estimated with the averaged score on the 'Vocabulary' and 'Block designs' subtests of either the Dutch version of the Wechsler Intelligence Scale for Children, third edition (WISC-III-NL) or the Dutch version of the Wechsler Adult Intelligence Scale, third edition (Vander Steene et al. 1986; Wechsler 1997). In children, these subtests have a correlation of 0.90 with the full-scale IQ (Sattler 1992). Details on the main characteristics of the DBD and HC adolescents group are shown in Table 1 . In the DBD+SD group $28 \%$ of the participants was dependent on alcohol, $48 \%$ on nicotine, $76 \%$ on marihuana and $24 \%$ of the participants used other drugs.

Iowa Gambling Task

A computerized version of the IGT was used to examine risky decision making (Bechara et al. 1994). Participants were instructed to win as much fictitious money as possible by picking one card at a time from any of the four decks (A, $\mathrm{B}, \mathrm{C}$, and $\mathrm{D}$ ) until the instruction was given to stop. Unbeknownst to the players, the task ends after 100 card selections. The four decks (40 cards each) vary with respect to immediate gains and risk of penalties. Selections from decks $A$ and $B$ yield average immediate gains of $€ 100$, whereas decks $\mathrm{C}$ and $\mathrm{D}$ on average give $€ 50$ for every card. In addition, each deck also carries certain penalties, such that in the long run the amount of penalties exceed the amount of gains in decks $\mathrm{A}$ and $\mathrm{B}$, and the amount of penalties are smaller than the amount of gains in decks $\mathrm{C}$ and $\mathrm{D}$. The optimal strategy is therefore to minimize the overall loss by avoiding the disadvantageous decks $\mathrm{A}$ and $\mathrm{B}$ in favor of advantageous decks $\mathrm{C}$ and D. Since the aim of the task is to win as much money as possible, decisions to choose from the advantageous decks $\mathrm{C}$ and $\mathrm{D}$ should therefore increase over time as a result of the reward and punishment schedules inherent to the task (Bechara et al. 1994).
Procedure

Testing took place at the institution where the participant stayed or at home. All participants were administered the same test-battery, consisting of the NIMH DISC-IV-C, WISC-IIINL or WAIS-III and the IGT. Cases where the participants reported they had used alcohol, cannabis or other drugs during the $24 \mathrm{~h}$ prior to testing were excluded from the study. Testing took approximately $4 \mathrm{~h}$ per participant. All volunteers received written and verbal information on the study protocol. Written informed consent was obtained from the participants and also parental assent in case the participant was younger than 18 years of age. Subjects received a 25 Euro gift certificate for participation. The study was approved by the Medical Ethical Review Committee of the University Medical Center Utrecht in accordance with the declaration of Helsinki.

\section{Data Reduction and Analyses}

Risky decision making was measured by dividing the 100 card selections into five blocks of 20 card selections (Bechara et al. 1994) and calculated by computing the mean percentage choices from the disadvantageous decks A and $\mathrm{B}$ for each block. Risky decision making was examined by performing an ANOVA over the five blocks with group [HC, DBD-SD, DBD+SD] as the between-subjects factor. Age and intelligence were entered as covariates (Blair et al. 2001; Evans et al. 2004). A separate ANOVA over the five blocks was performed to examine possible sex differences between the three groups [HC, DBD $+\mathrm{SD}, \mathrm{DBD}-\mathrm{SD}]$ in decision making. Total monetary outcome among the groups was investigated by running an ANOVA with group [HC, DBD+SD, DBD-SD] as the between subjects factor and age and intelligence as covariates. Where appropriate, a Greenhouse-Geisser correction was used. The significance level was set at 0.05 , two-tailed.

\section{Results}

Risky decision making was significantly influenced by age, $F(4,148)=3.35, p=0.01$, and intelligence, $F(4,148)=2.9$,

Table 1 Main characteristics of the DBD with (DBD+SD) and without substance dependence (DBD-SD) and healthy control (HC) adolescents group

\begin{tabular}{|c|c|c|c|c|}
\hline & $\begin{array}{l}\mathrm{HC} \\
(n=99)\end{array}$ & $\begin{array}{l}\text { DBD-SD } \\
(n=28)\end{array}$ & $\begin{array}{l}\mathrm{DBD}+\mathrm{SD} \\
(n=25)\end{array}$ & $\mathrm{p}$-value \\
\hline Age, mean $\pm \mathrm{SD}$, years & $17.5 \pm 1.9$ & $16.8 \pm 1.5$ & $17.5 \pm 1.8$ & $0.18^{\mathrm{i}}$ \\
\hline Intelligence, mean $\pm \mathrm{SD}$ & $88.8 \pm 19.2$ & $78.7 \pm 12.3$ & $82.3 \pm 15.2$ & $0.02^{\mathrm{i}}$ \\
\hline Male/female, $\mathrm{N}$ & $72 / 27$ & $23 / 5$ & $19 / 6$ & $<0.01^{\mathrm{ii}}$ \\
\hline
\end{tabular}

${ }^{\mathrm{i}}$ Analysis of variance

${ }^{\text {ii }} \chi^{2}$ test 
$p=0.02$. Older children and higher IQ scores were associated with reduced risky decision making. The test of between-subjects effects controlled for age and intelligence demonstrated a main effect of group, $F(2,150)=3.14, p<$ 0.05 . No main effect of sex, $F(1,151)=0.01, p=0.96$, and no group $\mathrm{x}$ sex interaction, $F(2,150)=1.13, p=0.32$, was found, suggesting that the significant main effect of group on risky decision making could not be explained by differences in male-female distribution across the three groups. Post-hoc least square difference (LSD) analyses controlling for age and intelligence showed that DBD+SD overall made more risky decisions than $\mathrm{HC}(p=0.05)$, and DBD-SD $(p=0.02)$, whereas no difference was observed between HC and DBD-SD $(p=0.31)$. Figure 1 displays overall percentage risky decision making for the $\mathrm{DBD}+\mathrm{SD}$ $(n=25)$, DBD-SD $(n=28)$ and HC group $(n=99)$. The ANOVA corrected for age and intelligence demonstrated a significant main effect of block, $F(4,148)=5.44, p<0.01$, $\varepsilon=0.75$, but no group $\mathrm{x}$ block interaction, $F(8,144)=0.44$, $p=0.89, \varepsilon=0.75$. Percentage risky decision making across the five blocks of the three groups is presented in Fig. 2. No group differences on monetary outcome were observed, $F(2,150)=2.33, p=0.1$.

\section{Discussion}

The aim of the present study was to examine the relationship between impaired decision making and SD in DBD adolescents. Results showed that DBD+SD adolescents demonstrated an overall preference for the

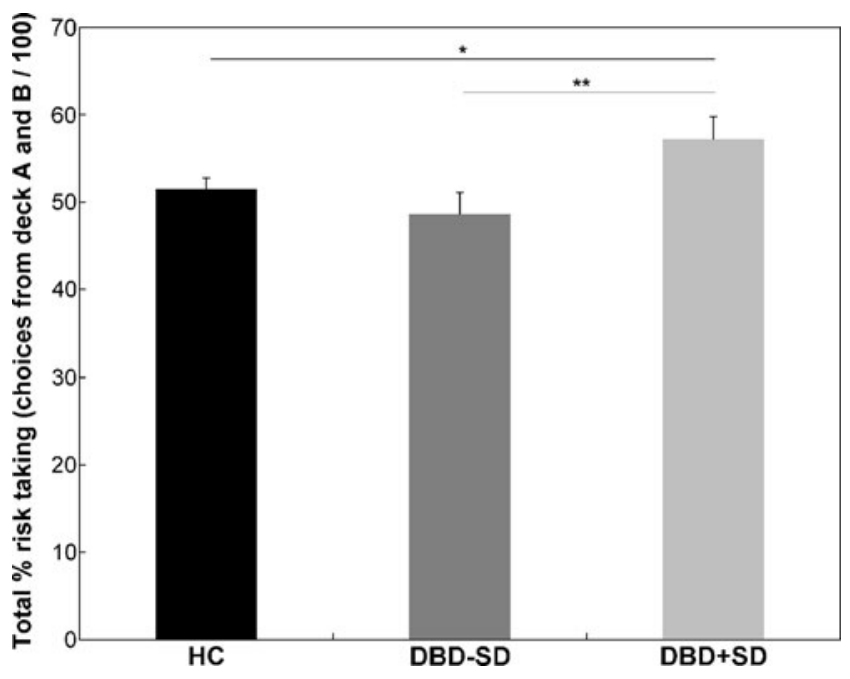

Fig. 1 Age- and intelligence-corrected mean \pm standard-error of the grand average percentage risk taking (i.e., total choices of deck $\mathrm{A}$ and $\mathrm{B} / 100)$ of the IGT in healthy controls (HC) and DBD adolescents without (DBD-SD) and with SD (DBD+SD). Covariates appearing in the model are evaluated at age $=17.37$ and intelligence $=85.89$. ${ }^{*} p=$ $0.05,{ }^{* *} p=0.02$

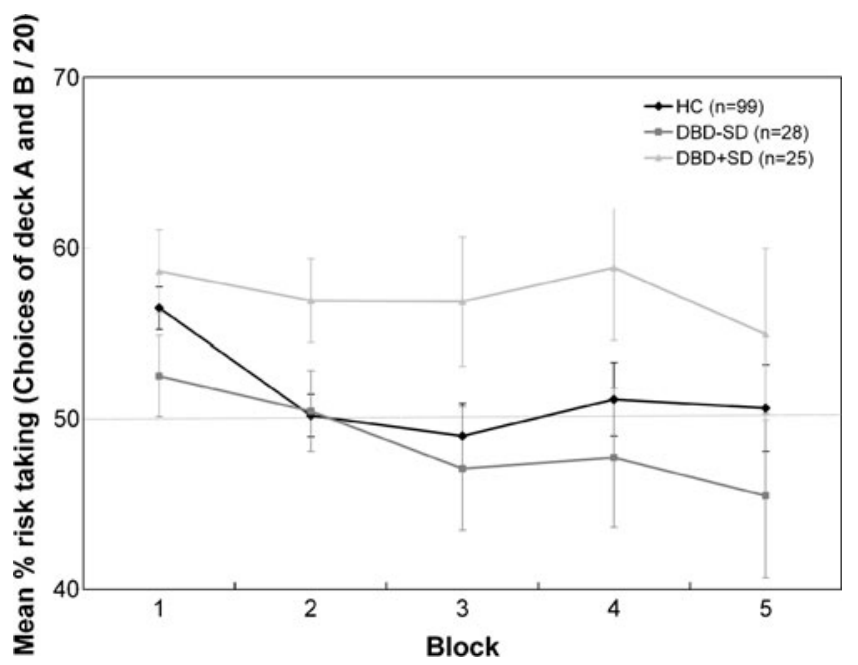

Fig. 2 Age and intelligence corrected mean \pm standard-error of the percentage risk taking (i.e., choices of deck A and B / 20) for each block of the IGT in healthy controls (HC), and DBD adolescents without (DBD-SD) and with substance dependence (DBD+SD). Covariates appearing in the model are evaluated at age $=17.37$ and intelligence $=85.89$

risky disadvantageous decks in comparison to DBD-SD and $\mathrm{HC}$ adolescents, whereas DBD-SD did not differ from $\mathrm{HC}$ adolescents on risk taking. However, DBD adolescents with and without SD did not demonstrate differences in risky decision making across the blocks during the IGT. The present study also showed that intelligence and age contribute to IGT performance (Blair et al. 2001; Evans et al. 2004).

Results of the present study suggest that risky decision making is not a general characteristic of DBD adolescents without ADHD co-morbidity. This result is not necessarily at variance with earlier findings by Ernst et al. (2003), Fairchild et al. (2009), and Luman et al. (2010) as samples in these studies did not consist of DBD-only adolescents. Therefore, our results emphasize the importance of considering the co-morbidity between ADHD and DBD, in order to properly understand the cognitive characteristics of these disorders. Rather, instead of being a general characteristic of $\mathrm{DBD}$, it may be that risky decision making, which has been found to be strongly associated with SD (Bartzokis et al. 2000; Bechara et al. 2001; Grant et al. 2000; Mazas et al. 2000), is a vulnerability factor for SD in a subgroup of adolescents with DBD. However, it is also possible that risky decision making is a reflection of the deleterious effects on behavior of excessive drug use in the DBD+SD.

Indeed, preclinical studies addressing the relationship between decision making and addictive behavior have shown that repeated or prolonged exposure to psychostimulant drugs such as amphetamine or cocaine increases the sensitivity for reward (Roesch et al. 2007), reduces the sensitivity to punishment signals during drug seeking 
(Deroche-Gamonet et al. 2004; Vanderschuren and Everitt 2004), and induces inflexible and perseverative behavior (Fletcher et al. 2005; Schoenbaum et al. 2004; Schoenbaum and Setlow 2005). Thus, drug-induced alterations in behavior may explain the enhanced risk taking we observed in $\mathrm{DBD}+\mathrm{SD}$.

On the other hand, severity of symptoms in terms of chronic dependence ( $>1$ year) and range of chronically abused substances in our sample did not have an effect on the percentage risk taking (both p-values $>0.27$ ). These results suggest that in spite of our small group sizes, increased risk taking in DBD adolescents with SD does not seem to be strongly mediated by chronic dependence. This observation concurs with animal studies showing that highly impulsive rats more rapidly develop symptoms of addiction than their less impulsive counterparts (Belin et al. 2008; Diergaarde et al. 2008). The faster onset of symptoms related to SD can therefore be explained by the fact that impulsivity is associated with an imbalance between the reward and punishment systems (Potts et al. 2006; Smillie and Jackson 2006), supporting the notion that impaired decision making may precede and importantly contribute to the development of SD in DBD.

Together, these findings highlight the complex interactions between the vulnerability to SD on the one hand, and the detrimental effects of drug exposure on the other hand. The present results show that increased risk taking is associated with DBD+SD, underscoring the need for further research on the relationship between reward and punishment sensitivity, perseverative behavior, substance use and decision making in DBD (Rogers and Robbins 2001).

We wish to note that risky decision making by itself does not necessarily imply abnormal decision making or a psychopathological condition. A balance between acquired knowledge as reflected by the decline in risky decision making during the course of the game and the exploration of new options in terms of incidental risk taking has been suggested to be the optimal behavioral strategy to seek and exploit new opportunities to maximize profit (Daw et al. 2006). However, in order to maximize gains on the IGT, an optimal balance between exploration and exploitation is necessary, and the increases in risk taking as observed here in DBD+SD usually lead to reduced profits on the task. Unfortunately, in spite of increased risky decision making by $\mathrm{DBD}+\mathrm{SD}$ adolescents, no group differences in monetary outcomes were observed. A possible explanation might be that the use of real instead of facsimile money may increase risky decision making (Bowman and Turnbull 2003). The fact that we used facsimile money in the present study may have prevented us from finding a significant group difference on monetary outcome. In other words, due to the hypothetical payments we cannot rule out the possibility that some participants may not have taken the task seriously. Finally, we controlled for the confounding effects of age, intelligence and ADHD diagnoses in our sample, subsequently increasing homogeneity of the group but at the expense of statistical power.

Decision making is one of the cognitive skills that individuals use to solve everyday social problems. Children and adolescents, indeed, have at their disposal a series of cognitive skills such as defining the problem, generating possible solutions and deciding which solution will be implemented (Crick and Dodge 1994). Deviances in all these skills have been found in children with aggressive behavior and DBD (Matthys and Lochman 2010). Specifically, with respect to the response decision step it has been shown that DBD children more often select an aggressive response and less often select a prosocial response when compared with normal controls (Matthys et al. 1999). Cognitive behavioral treatment such as the Coping Power program (Lochman and Wells 2002) targets these problem solving skills, for example by assisting children to better anticipate the consequences they may experience for their solutions to their social problems. It has been shown that this program for DBD in middle childhood is more powerful than usual care in reducing substance use in early adolescence (Zonnevylle-Bender et al. 2007). The present study suggests that risky decision making may be included in problem solving skills training in view of preventing SD in DBD children and adolescents.

In conclusion, the results of the present study suggest that increased risk taking instead of being a general characteristic of adolescents with DBD without ADHD co-morbidity, may be associated with the development of $\mathrm{SD}$ in a subgroup of these adolescents.

Acknowledgements The authors would like to thank all the volunteers and the following institutions: JJI De Heuvelrug, De Waag, Barentsz (Altrecht), De Derde Oever (De Bascule), De Fjord (ParnassioBavogroep). We would like to acknowledge Maria de Glint, Renske Houben, Azra Krdzalic, Kim van der Lelij and Marijke ter Veer for assistance in collecting the data. This work was supported by the ZonMw Addiction Program (3110001), the Netherlands, and the National Institute on Drug Abuse (R01 DA 16135), United States of America. Disclosure: The authors report no conflicts of interest.

Open Access This article is distributed under the terms of the Creative Commons Attribution Noncommercial License which permits any noncommercial use, distribution, and reproduction in any medium, provided the original author(s) and source are credited.

\section{References}

American Psychiatric Association (2000). Diagnostic and statistical manual of mental disorders, $4^{\text {th }}$ ed., Text revision (DSM-IV-TR). Washington, DC, American Psychiatric Association.

Bartzokis, G., Lu, P. H., Beckson, M., Rapaport, R., Grant, S., Wiseman, M., et al. (2000). Abstinence from cocaine reduces 
high-risk response on a gambling task. Neuropsychopharmacology, $22,102-103$.

Bechara, A., Damasio, A. R., Damasio, H., \& Anderson, S. W. (1994). Insensitivity to future consequences following damage to human prefrontal cortex. Cognition, 50, 7-15.

Bechara, A., Dolan, S., Denburg, N., Hindes, A., Anderson, S. W., \& Nathan, P. E. (2001). Decision-making deficits, linked to a dysfunctional ventromedial prefrontal cortex, revealed in alcohol and stimulant abusers. Neuropsychologia, 39, 376-389.

Bechara, A., Dolan, S., \& Hindes, A. (2002). Decision-making and addiction (part II): myopia for the future or hypersensitivity to reward? Neuropsychologia, 40, 1690-1705.

Belin, D., Mar, A. C., Dalley, J. W., Robbins, T. W., \& Everitt, B. J. (2008). High impulsivity predicts the switch to compulsive cocaine-taking. Science, 320, 352-355.

Biederman, J., Monuteaux, M. C., Mick, E., Spencer, T., Wilens, T. E., Silva, J. M., et al. (2006). Young adult outcome of attention deficit hyperactivity disorder: a controlled 10-year follow-up study. Psychological Medicine, 36, 167-179.

Blair, R. J. R., Colledge, E., \& Mitchell, D. G. V. (2001). Somatic markers and response reversal: is there orbitofrontal cortex dysfunction in boys with psychopathic tendencies? Journal of Abnormal Child Psychology, 29, 499-511.

Blum, K., Braverman, E. R., Holder, J. M., Lubar, J. F., Monastra, V. J., Miller, D., et al. (2000). Reward deficiency syndrome: a biogenetic model for the diagnosis and treatment of impulsive, addictive, and compulsive behaviors. Journal of Psychoactive Drugs, 32, 1-112.

Bowman, C. H., \& Turnbull, O. H. (2003). Real versus facsimile reinforcers on the Iowa gambling task. Brain and Cognition, 53, 207-210.

Costello, E. J., Mustillo, S., Erkanli, A., Keeler, G., \& Angold, A. (2003). Prevalence and development of psychiatric disorders in childhood and adolescence. Archives of General Psychiatry, 60, 837-844.

Crick, N. R., \& Dodge, K. A. (1994). A review and reformulation of social information-processing mechanisms in children's social adjustment. Psychological Bulletin, 115, 74-101.

Daugherty, T. K., \& Quay, H. C. (1991). Response perseveration and delayed responding in childhood behavior disorders. Journal of Child Psychology and Psychiatry, 32, 453-461.

Daw, N. D., O’Doherty, J. P., Dayan, P., Seymour, B., \& Dolan, R. J. (2006). Cortical substrates for exploratory decision making. Nature, 441, 876-879.

Deroche-Gamonet, V., Belin, D., \& Piazza, P. V. (2004). Evidence for addiction-like behavior in the rat. Science, 305, 1014-1017.

Diergaarde, L., Pattij, T., Poortvliet, I., Hogenboom, F., de Vries, W., et al. (2008). Impulsive choice and impulsive action predict vulnerability to distinct stages of nicotine seeking in rats. Biological Psychiatry, 63, 301-308.

Disney, E. R., Elkins, I. J., McGue, M., \& Iacono, W. G. (1999). Effects of ADHD, conduct disorder, and gender on substance use and abuse in adolescence. American Journal of Psychiatry, 156, $1515-1521$

Ernst, M., Grant, S. J., London, E. D., Contoreggi, C. S., Kimes, A. S., \& Spurgeon, L. (2003). Decision making in adolescents with behavior disorders and adults with substance abuse. American Journal of Psychiatry, 160, 33-40.

Evans, C. E. Y., Kemish, K., \& Turnbull, O. H. (2004). Paradoxical effects of education on the Iowa Gambling Task. Brain and Cognition, 54, 240-244.

Fairchild, G., van Goozen, S. H. M., Stollery, S. J., Aitken, M. R. F., Savage, J., Moore, S. C., et al. (2009). Decision making and executive function in male adolescents with early-onset or adolescence-onset conduct disorder and control subjects. Biological Psychiatry, 66, 162-168.
Fergusson, D. M., Horwood, L. J., \& Ridder, E. M. (2007). Conduct and attentional problems in Childhood and adolescence and later substance use, abuse and dependence: results of a 25-year longitudinal study. Drug and Alcohol Dependence, 88, S14-S26.

Fletcher, P. J., Tenn, C. C., Rizos, Z., Lovic, V., \& Kapur, S. (2005). Sensitization to amphetamine, but not PCP, impairs attentional set shifting: reversal by a D1 receptor agonist injected into the medial prefrontal cortex. Psychopharmacology, 183, 190-200.

Giancola, P. R., Peterson, J. B., \& Pihl, R. O. (1993). Risk for alcoholism, antisocial behavior, and response perseveration. Journal of Clinical Psychology, 49, 423-428.

Grant, S., Contoreggi, C., \& London, E. D. (2000). Drug abusers show impaired performance in a laboratory test of decisionmaking. Neuropsychologia, 38, 1180-1187.

Hicks, B. M., Krueger, R. F., Iacono, W. G., McGue, M., \& Patrick, C. J. (2004). Family transmission and heritability of externalizing disorders: a twin-family study. Archives of General Psychiatry, 61, 922-928.

Jentsch, J. D., Olausson, P., De La Garza, R., 2nd, \& Taylor, J. R. (2002). Impairments of reversal learning and response perseveration after repeated, intermittent cocaine administrations to monkeys. Neuropsychopharmacology, 26, 183-190.

Kim-Cohen, J., Caspi, A., Moffitt, T. E., Harrington, H., Milne, B. J., \& Poulton, R. (2003). Prior juvenile diagnoses in adults with mental disorder: developmental follow-back of a prospectivelongitudinal cohort. Archives of General Psychiatry, 60, 709717.

Lochman, J. E., \& Wells, K. C. (2002). Contextual social-cognitive mediators and child outcome: a test of the theoretical model in the Coping Power Program. Development and Psychopathology, 14, 971-993.

Luman, M., Sergeant, J. A., Knol, D. L., \& Oosterlaan, J. (2010). Impaired decision making in oppositional defiant disorder related to altered psychophysiological responses to reinforcement. Biological Psychiatry (in press).

Matthys, W., \& Lochman, J. E. (2010). Oppositional defiant disorder and conduct disorder in childhood. Chichester: Wiley-Blackwell.

Matthys, W., van Goozen, S. H. M., de Vries, H., Cohen-Kettenis, P., \& van Engeland, H. (1998). The dominance of behavioural activation over behavioural inhibition in conduct disordered boys with and without attention deficit hyperactivity disorder. Journal of Child Psychology and Psychiatry, 39, 643-651.

Matthys, W., Cuperus, J., \& Van Engeland, H. (1999). Deficient social problem-solving in boys with $\mathrm{ODD} / \mathrm{CD}$, with $\mathrm{ADHD}$, and with both disorders. Journal of the American Academy of Child and Adolescent Psychiatry, 38, 311-321.

Matthys, W., van Goozen, S. H. M., Snoek, H., \& van Engeland, H. (2004). Response perseveration and sensitivity to reward and punishment in boys with oppositional defiant disorder. European Child and Adolescent Psychiatry, 13, 362-364.

Mazas, C. A., Finn, P. R., \& Steinmetz, J. E. (2000). Decision-making biases, antisocial personality, and early-onset alcoholism. Alcoholism: Clinical and Experimental Research, 24, 1036-1040.

Merikangas, K. R., \& Avenevoli, S. (2000). Implications of genetic epidemiology for the prevention of substance use disorders. Addictive Behaviors, 25, 807-820.

O'Brien, B. S., \& Frick, P. J. (1996). Reward dominance: associations with anxiety, conduct problems, and psychopathy in children. Journal of Abnormal Child Psychology, 24, 223-240.

Potts, G. F., George, M. R., Martin, L. E., \& Barratt, E. S. (2006). Reduced punishment sensitivity in neural systems of behavior monitoring in impulsive individuals. Neuroscience Letters, 397, $130-134$.

Roesch, M. R., Takahashi, Y., Gugsa, N., Bissonette, G. B., \& Schoenbaum, G. (2007). Previous cocaine exposure makes rats 
hypersensitive to both delay and reward magnitude. Journal of Neuroscience, 27, 245-250.

Rogers, R. D., \& Robbins, T. W. (2001). Investigating the neurocognitive deficits associated with chronic drug misuse. Current Opinion in Neurobiology, 11, 250-257.

Rutter, M., Kim-Cohen, J., \& Maughan, B. (2006). Continuities and discontinuities in psychopathology between childhood and adult life. Journal of Child Psychology and Psychiatry, 47, 276-295.

Sattler, J. M. (1992). Assessment of childhood (3rd edn, rev. and updated). San Diego: Sattler.

Schoenbaum, G., \& Setlow, B. (2005). Cocaine makes actions insensitive to outcomes but not extinction: implications for altered orbitofrontal-amygdalar function. Cerebral Cortex, 15, 1162-1169.

Schoenbaum, G., Saddoris, M. P., Ramus, S. J., Shaham, Y., \& Setlow, B. (2004). Cocaine-experienced rats exhibit learning deficits in a task sensitive to orbitofrontal cortex lesions. European Journal of Neuroscience, 19, 1997-2002.

Shaffer, D., Fisher, P., Lucas, C. P., Dulcan, M. K., \& Schwab-Stone, M. E. (2000). NIMH diagnostic interview schedule for children version IV (NIMH DISC-IV): description, differences from previous versions and reliability of some common diagnoses. Journal of the American Academy of Child and Adolescent Psychiatry, 39, 28-38.

Shapiro, S. K., Quay, H. C., Hogan, A. E., \& Schwartz, K. P. (1988). Response perseveration and delayed responding in undersocialized aggressive conduct disorder. Journal of Abnormal Psychology, 97, 371-373.
Smillie, L. D., \& Jackson, C. J. (2006). Functional impulsivity and reinforcement sensitivity theory. Journal of Personality, 74, 47-84.

Toplak, E. M., Jain, U., \& Tannock, R. (2005). Executive and motivational processes in adolescents with Attention-Deficit-Hyperactivity Disorder (ADHD). Behavioral and Brain Functions, 1, 1-8.

Van Goozen, S. H. M., Cohen-Kettenis, P. T., Snoek, H., Matthys, W., Swaab-Barneveld, H., \& van Engeland, H. (2004). Executive functioning in children: a comparison of hospitalized ODD and ODD/ADHD children and normal controls Journal of Child Psychology and Psychiatry, 45, 284-292.

Vander Steene, G., van Haassen, P. P., de Bruyn, E. E. J., Coetsier, P., Pijl, Y. J., Poortinge, Y. H., et al. (1986). WISC-R Nederlandstalige uitgave: Verantwoording. Lisse: Swets \& Zeitlinger.

Vanderschuren, L. J. M. J., \& Everitt, B. J. (2004). Drug seeking becomes compulsive after prolonged cocaine self-administration. Science, 305, 1017-1019.

Wechsler, D. (1997). Wechsler Adult Intelligence Scale, third edition (WAIS-III-R): Dutch version. Lisse: Swets and Zeitlinger.

Young, S. E., Mikulich, S. K., Goodwin, M. B., Hardy, J., Martin, L., Zoccolillo, M. S., et al. (1995). Treated delinquent boys' substance use: onset, pattern, relationship to conduct and mood disorders. Drug and Alcohol Dependence, 37, 149-162.

Zonnevylle-Bender, M. J., Matthys, W., van de Wiel, N. M., \& Lochman, J. E. (2007). Preventive effects of treatment of disruptive behavior disorder in middle childhood on substance use and delinquent behavior. Journal of the American Academy of Child and Adolescent Psychiatry, 46, 33-39. 